\title{
The Status of the Humanities in The 21st Century: A Case Study
}

\author{
Ruth Dorot \\ Nitza Davidovitch \\ Ariel University, Israel
}

Doi:10.19044/ejes.v7no3a9 URL:http://dx.doi.org/10.19044/ejes.v7no3a9

\begin{abstract}
From the time of ancient Greece until late nineteenth-century Europe, the humanities enjoyed a status of respect and prestige. From the latter half of the 1990s, their status and prestige dropped, mainly due to the low economic value of the humanities for a goal-oriented generation and due to the limited representation of humanities graduates in centers of power and employment. The current study illuminates the efforts of Israel's institutions of higher education to attract students and the need for the humanities in 2020. The article explores the resources involved in the study, thought, psychological comprehension, knowledge base, and aesthetic development characteristic of humanities disciplines. Select examples from the field of the arts illustrate the humanities' unique contribution to a world focused on technology, science, and the pursuit of money and profit.

This study focuses on Israel as a case study that illuminates the status of the humanities in institutions of higher education around the world. The state of these studies in Israel was explored through learning products approach and ways of coping with the challenges of the twenty-first century, and highlights the significance of humanities studies in the technological world into which contemporary academic institutions have been drawn. This research discusses the paradigmatic change in higher education from contentcentered to learning-centered academic programs and from STEM to STEAM.
\end{abstract}

Keywords: Humanities, STEM, STEAM, art. 


\section{Introduction}

\section{About the humanities, humanistic and human culture studies, and Jewish studies}

The humanities is a general name for several disciplines that include philosophy, the arts, and languages and deal with human fields of interests (Triger, 2007), unlike disciplines that deal with the study of processes, nature (physics and chemistry), and social relations (sociology and economics). As defined by Israel's Council for Higher Education, the disciplines of the humanities also include Jewish studies (Davidovitch, 2004) and humanistic and human culture studies (Yisraeli, 2020).

The humanities investigate the various displays of human spirit as well as the products of human creativity throughout history. Namely, students examine human actions with regard to the unique reality in a certain time and place, as affecting the universal essence of life and its meanings in various cultures. Scholars in the humanities explore various dimensions of human life throughout human history and culture. Students study that which human beings generated for themselves in language and its symbols, religion and law, government, ideology and worldviews, ritual and myth, literature and poetry, philosophy and art, math and philosophy, hermeneutics and the history of science, history and music, architecture and sculpture, folklore and timedependent consciousness, written memory and constantly renewed creativity in the expanses of human thought with its uniqueness and changing diversity (Furstenberg, 2020). The humanities also deal with unique skills that involve cultivating intellectual inquisitiveness, hidden creativity, the history of science, formulating new problems, and asking new questions. In addition, they have a unique value-based contribution to imparting and advancing knowledge, truth, and justice, liberty and equality, morals and benevolence, justice and peace (Elior, 2011).

The term "humanistic studies" is based on the classical conception whereby the aims of the humanities are to forge a person with general knowledge education and open mind and to create an intellectual society that encourages the development of culture, ethics, and sociopolitical values (Lamm, 1993, 1999). For the philosopher Plato, spiritual matters were the only route to a meaningful life. He saw in the intellectual the passion to seek truth, wisdom, beauty, and good (Goldman, 2014). The humanities may be said to be a manifestation of all disciplines that express human culture and the product of human creativity, including in the Jewish world (Yisraeli, 2020).

\section{The change in the status of the humanities in academia}

The elitist status of the humanities was maintained from ancient Greece to late nineteenth-century Europe, strengthening the association between education and personal excellence, a solid foundation in the 
humanities, and their instruction. The conception of education was based on the belief that educating for excellence requires a study of the humanities. In contrast to the current conception, the humanities were perceived as practical studies that provide tools essential for realizing one's goals, and a means for success and achievements. These studies were perceived not as a luxury but rather as essential for one's adjustment to life. The humanities maintained their status despite the crises in the history of the West, as well as the ethical crisis (Rinon, 2014).

Beginning from the latter half of the 1990s, a change was evident in the attitude to the humanities in Israel. Humanities programs began losing students. Their numbers dropped significantly from $18.5 \%$ in 1996 to $11.7 \%$ in $2001,9.5 \%$ in 2006 , and only $7.4 \%$ in 2013 . The low demand for the humanities is also evident in the decline in the number of candidates, from about 6,330 in the early 2000s to some 4,200 in 2012/13 (Council for Higher Education, 2013). An example of this drop in the Literature program at the Hebrew University: In the 2008/9 academic year, only 18 students registered to the Hebrew Literature program at the Hebrew University of Jerusalem, a miniscule number compared to more than 200 students in the program in the 1950s (Shamir, 2009, 2012). This resembles trends throughout the world (Furstenberg, 2020).

The decline in demand for the humanities also led to a decline in the number of faculty members employed in teaching these disciplines. Research findings (Frank \& Gabler, 2006) indicate that the number of lecturers in the humanities has diminished dramatically. From 1995 their number dropped by $41 \%$, while the number of faculty members in the social sciences increased by $222 \%$ (Asis, 2020).

Another illustration of this trend is the decline in the status of Bible studies in Israel. Ben Ayun (2011) describes several causes for the declining status of Bible studies. In addition to the global decline in the status of the humanities, shifting forces are influencing the world of education and leading to accelerated growth of the technological disciplines at the expense of the humanities. Zakovitch (2005) discusses another cause of the depreciation in the status of the humanities - the distance between the Bible and the student's world, as manifested in the lifestyles of the figures described and in the linguistic style that is incomprehensible to students.

\section{Learning-focused teaching and backward course design - from STEM to STEAM (Davidovitch \& Shiller, 2016).}

Art and science both hinge on discovery, and discovery requires thinking out of the box. But how do you lead students to think creatively in STEM education? The answer is STEAM, and A is for the arts. STEAM - the integration of music, visual arts, and drama into daily STEM 
instruction-has been proven to enhance student achievement in STEM subjects. After all, creative, real-world problem solving is what working scientists and mathematicians actually do. But how do busy STEM educators weave arts activities into a sometimes-inflexible STEM curriculum?

\section{Obstacles encountered by students of the humanities}

Currently, young people wishing to study the humanities encounter barriers. We analyze these barriers from two points of view - the socialsociological perspective and the economic perspective (Furstenberg, 2020).

\section{The social-sociological perspective}

- The Jewish humanities are not popular (Shamir, 2012).

- There is a decline in the academic standards of students accepted to these courses of study (due to lower/more accommodating admission requirements). Outstanding students are attracted to prestigious and highly regarded programs, and therefore those who apply to humanities know that they are not regarded as prestigious programs (Shenhar, 2007).

- Students regard these disciplines as old-fashioned and irrelevant for modern life (Shenhar, 2007).

\section{The economic perspective}

- The humanities reflect a socioeconomic phenomenon characterized by globalization, privatization, and capitalism. Young people seek profitability and utilitarianism (Shamir, 2009, 2012).

- There is also a problem with regard to faculty members in the humanities. Only at around age 50 do faculty members in the humanities earn tenure, and until then they risk finding themselves outside academia and destitute. Hence, there is no incentive that motivates individuals to apply for studying the humanities (Shamir, 2009,2012).

\section{Jewish studies - Particular and Universal Aspects}

Jewish studies occupy an important place in Jewish culture. Some claim (Yisraeli, 2020) that the massive entrance of the colleges to the field of undergraduate programs in Jewish studies, and in recent years in graduate programs, has increased the competition within Jewish studies, and that the universities are not up to the competition. The admission terms at the colleges are more accommodating - creating a competition among the students who the universities do not want and for whom university studies are beyond their capabilities.

However, in the case of PhD studies, Yisraeli (2020) says that the field is flourishing as never before, both in Israel and elsewhere. This is particularly surprising due to the fact that PhD students know that their chances of finding a job in academia are scarce. People pursue doctoral degrees in humanities out 
of a desire to engage in research and to continue their research outside academia as well, based on a true interest in the field and because the subject of their research is important for them.

With regard to the profile of the research students, it is evident that:

1. There is a considerable proportion of graduates of religious schools among research students in the humanities (Yisraeli,2020). This is only natural. These are knowledgeable students in Jewish studies who seek to pursue advanced studies in order to acquire new tools and receive guidance in studying and research. They also find gratification in academic work, and the pursuit of Jewish studies is an important value for them.

2. Yisraeli (2020) notes that a considerable share of the students come from the field of education and teach in the humanities.

3. Some choose to study for a PhD in Jewish studies although they come from other fields such as hi-tech, in the search for spiritual realization. For these students, Jewish studies represent a field of interest that is beyond the applied or purposeful.

Prof. Vered Noam (2020) calls this phenomenon in the humanities of multiple students earning advanced degrees and few undergraduate students an upsidedown pyramid. Noam too identifies an increase in Jewish students, and addresses this from an international view. She notes that beginning from the mid-twentieth century, the major share of international research in Jewish studies was conducted in Israel. Today there is extensive research in the US and Europe as well.

In addition, there are developments in the field of computerization, and the digital humanities are opening up new possibilities. Many original materials are available on the Internet. For example, the Cairo Genizah, all the Qumran scrolls - materials that were not accessible in the 1990s. The result is an abundance of research and development of new perspectives on familiar subjects. For instance, there are new literary readings of ancient texts, and efforts in comparative inter-religious research, and more. Nonetheless, the crisis in the humanities cannot be disregarded and, in some respects, it is even graver in Jewish studies, particularly in undergraduate programs (Noam, 2020).

Noam (2020) points to a series of reasons: the risks of postmodernism, economic factors, and the political and social circumstances in Israel. At the same time, she notes the resurgence in Jewish studies, both around the world and in Israel. She sees this as natural, as the humanities pertain to that which is beautiful, to the meaning of life, human hope, the sources of culture, the humane - and as long as there are human beings, there will also be a desire and longing for the humanities and their values. She views the current decline of the humanities as a temporary and passing anecdote in the history of the 
human spirit, a crisis from which something new will emerge. Noam (2020) notes that maintaining the diverse world of the humanities is a basic condition of a free society that recognizes the value of culture and discourse. Moreover, the humanities are an essential tool for knowledge of both Jewish and general history, culture, and philosophy, specifically in a world in which boundaries are constantly being breached. She claims (2020) that it is not possible to understand that contemporary events in Europe, the US, the Muslim world, orand in general, to maintain a dialogue with people and societies around the world, without knowledge in the cultural and religious foundation that the humanities provide. Noam (2020) adds that Jewish culture can contribute to general and inter-religious studies in the humanities, and play a role as the source of Jewish cultural treasures. The challenge encountered by academia in general is to make cultural and spiritual treasures relevant, up to date (Yisraeli, 2020). We must be attentive to topics that interest today's young people and make adaptations. The question is - how?

\section{The humanities: Spiritual assets}

As the popularity of the humanities declines, their objective and deep significance increases. A world that lacks these disciplines will lack human sensitivity and feeling, warmth and honest friendship. In societies with a strong technological orientation, such as Japan where there is a general atmosphere of "workaholism," there is a conspicuous absence of quality leisure time that digital means are unable to fill. Quality leisure is essential for one's mental health. The occupation with science, space, medicine, and the financial world with all it entails, has justifiably taken over the world, but without the rich world encompassed by the humanities our world will become barren, estranged, robotic, and lack vitality. High culture and spirituality certainly advance humanity and have the potential to enhance people's lives. To examine the contribution of the humanities to individuals and to the collective, we chose the history of art as an illustrative discipline. The plastic arts, which include painting and drawing, sculpture with various materials, and architecture, have expanded human knowledge and provided intellectual tools for life (Dorot, 2013). Literature with its various genres, in addition to being a source of pleasure and entertainment, is also capable of developing life skills such as psychological understanding of others, an ability to feel empathy for others, analyses of historical and geographical conditions, and even healing through bibliotherapy.

In the following examples we demonstrate several areas that are expressed in these and that contribute to our intellectual enrichment, satisfy our curiosity, enhance our ability to deal with complex psychological states, and more (Richards, 2017). Occupation with the arts and with other artistic disciplines raises human beings and the level of their intellectual and aesthetic 
reasoning, which makes it possible to surpass the limited narrow reality and helps students develop a comprehensive perspective on life.

A visual source of knowledge about the ancient world, and a gesture to the classical world that served as a source of inspiration for Renaissance artists, was provided by Raphael Sanzio (1483-1520) during the years 15091511, in his monumental fresco The School of Athens (Figure 1), in the Stanza della Siegnatura at the Vatican in Rome. This room is one of four halls in the living quarters of Pope Julius II that Raphael was asked to redecorate. The fresco is an extensive visual depiction and song of praise for the Platonian Academy and classical Greek philosophy, including Greek sages with their various occupations and vocations. For the first time in Western art, an artist managed to form a harmonious unity, bringing together well-known figures of the ancient era, side by side with his own contemporaries. This wall is an excellent example of how it is possible to attain aesthetic-visual pleasure and moreover, allows us to learn about two periods concurrently: the ancient classical world and the Renaissance. Indeed, Raphael was not personally acquainted with the classical world, but through the admiration that he and his peers felt for ancient Greece and its values he managed to reproduce this reality from his imagination and plant it in his own era. Furthermore, the decorated space contains those special figures who symbolize the desired connection between the forces of the soul and the forces of the mind, between investigation of the source of the universe and research of the good life and happiness - the main topics of ancient philosophy.

The painting portrays 21 Greek philosophers, scientists and mathematicians, authors, poets and architects, who lived in various periods in history, whom Raphael brought together in a momentous magnificent space framed by classical architecture, standing, sitting, walking, arguing, studying, talking, working, or playing, in a system of elliptical movement that begins in the foreground and ends at the center of the background. Among these are Socrates in a deep argument, as well as Archimedes, Euclid, Pythagoras, Ptolemy, and Bramante. Raphael connects the painting, nature, architecture, and sculpture, and includes sculptures of Apollo god of light, archery, and music, holding a lyre, and of Athena the Greek goddess of wisdom presented in her Roman guise as Minerva.

To enhance the harmony and build bridges between the Renaissance present and the classical past, the artist gave the Greek sages the facial features of contemporary figures: Plato, for instance, received the face of Leonardo da Vinci, the artist and scientist who was Raphael's contemporary, while Heraclitus received that of Michelangelo, also a contemporary of Raphael's. The space, which begins at the center of the exact geometric tiles in the area close to the observer and, based on the best mathematical knowledge at the time, creates perfect depth and is a constitutive example of the Renaissance 
desire to use the laws of perspective to build a "correct appearance": This fresco reflects the illusory architecture that conveys trustworthiness, historical human diversity, and nature - the blue sky strewn with clouds.

The ceiling is constructed of four arcs, beginning from the large outer one that is closest to the observers. The arcs are a gesture to Roman builders. At the center of the painting, under the central arc, Raphael placed Plato and Aristotle, where the latter is looking at his teacher walking beside him, both deep in conversation, probably discussing the philosophies symbolized by the books they are holding. Plato, emblematic of the divine and the mysterious nature of the universe, is wearing a red cape and portrayed as a scholar with white hair and beard. He is barefoot and is standing on his toes, rising in the direction of his right hand that is pointing vertically to heaven - "the seat of all ideas" - as in his book on the absolute ideas, "Timaeus" (Dancy, 2004). This book, which is an essay on the universe, includes the theories of forms and deals with space, time, eternality; it was utilized by the mathematical sciences for a millennium. Aristotle, who symbolizes reality and the "here and now", wears a blue cape, and is taller and younger than Plato. He is a vital, handsome man, wearing sandals and fashionable clothes, the more realistic of the two. He is holding out his arm horizontally, parallel to the ground towards corporeal reality, similar to the orientation of his book, "Nicomachean Ethics" (ibid.), which presents his empirical ideas that analyze the world we live in and explore the physicality of life and the realistic realm. As he sees it, the purpose of ethics is practical and not theoretical: not knowledge for the sake of knowledge.

Plato's "Theory of Ideas" is to a large degree a response to the sophists' argument of the impossibility of gaining familiarity with a world whose characteristic principle is constant change, which transforms all knowledge into hypothetical knowledge and that renders any knowledge as uncertain. In his "Theory of Ideas", Plato determines that material reality is not the only realm and that there is another domain, that of ideas. This domain of reality is much more realistic because it is not corporeal and therefore exists eternally, unchanged. Since the world of ideas is not corporeal it cannot be grasped by the senses and requires cognition and the mind. Finally, the ideas that Plato suggests in his "Theory" do not depend on human beings or on their physical existence. As a result, these ideas are objective and always correct. For instance, in the corporeal world it is possible to argue about what is beautiful, but in the world of ideas there is one constant and eternal theory of beauty. According to this theory, the world of ideas is real, whole, and good, and every object and quality in the corporeal world has a parallel in the world of ideas. Not all the ideas are necessarily realized in the corporeal world but everything in the latter is a derivative of perfect ideas" (ibid., p. 19). 
According to philosopher Marcilio Ficino (1499-1433), the two directions indicated by the arms of Plato and Aristotle symbolize the supreme quality of Plato's contemplation of ideas, which points upwards, and the positivist spirit of his disciple, who points horizontally (Encyclopedia of Art Education) (http://www.visual-arts-cork.com/famous-paintings/school-ofathens.htm). Plato and Aristotle appear to complement each other. Raphael framed them in an arc and thus stressed their essential unity and granted them a unique identity that distinguishes them from all the other philosophers present. By stressing the dramatic difference between the directions of their arms, Raphael depicted the transcendental and metaphysical nature of Plato's philosophy versus the corporeal-practical nature of Aristotle's lectures. Raphael's distinction between the two raises basic epistemological questions that touch upon the source, nature, methods, and limits of personal knowledge, such as, what is the source of our knowledge concerning reality? Is there a difference between knowledge originating from divine revelation and knowledge originating from empirical observation and the training of human logic?

The hands in the center of the work express a philosophical concept. Plato, whose book is, as stated, held vertically, is pointing upward because he posited that the changing world that we experience is a mere shadow of a higher, eternal and unchanging reality. This reality, which comes from another world, is supreme, and serves as the site of beauty, justice, and wisdom. In complete contrast to Plato, Aristotle, whose arm and book are parallel to the ground, believes that the only reality is that which we can see and experience through our senses. His book emphasizes relationships, justice, friendship, and governance in the human world, as well as the need to learn them (Figure 1).

Another example that demonstrates the possibility of learning historical facts in a creative and interesting way, but even more so an encounter with an interesting psychological story that teachers human empathy even in times of war, is the meeting of the two generals at the center of the monumental painting "The Surrender of Breda" or "The Lances" by Spanish artist Diego Velázquez (1599-1660), painted in 1634-1635 (Figure 2). Velázquez depicted the Marquis General Ambrogio Spinola of Genoa, who conquered the city of Breda in the Netherlands in 1625, in a campaign by the Flanders who were loyal to the King of Spain against the Dutch who had rebelled against the Habsburg Empire (Pepper, 2011).

Many link "The Surrender of Breda" to the Alexander Mosaic from Pompeii, and see the Surrender as a paraphrase on the mosaic, which depicts the Battle of Issus between Alexander the Great and the vanquished Darius III. For example, elements such as the spears in the background and the outstretched hand appear in both paintings. Velázquez's biographer, Carl Justi, 
noted that both artworks anthropomorphize a historical event by focusing on the emotions expressed by the main characters.

The conquest of the fortified city Breda was one of the impressive military successes of the Spanish in the later stages of the Thirty-Year War between Holland and Spain. Prior to the conquest, the Spanish government decided to make do with imposing an economic siege on Holland, as an alternative to employing military force. Nonetheless, General Spinola took his soldiers and attacked the city. Underlying the fighting was his personal rivalry with Dutch General Justin of Nassau. Four years later (1629), Velázquez became acquainted with Spinola, who died in 1630, and even joined him for a trip to Italy. In 1637, Breda was occupied by the Dutch. Velázquez painted the story of the city's surrender several years after the battle, as a national gesture, but mainly in gratitude to Spinola whose fame had already become an event of the past as a result of a military failure in a war between Spain and France in Northern Italy. The painting salutes the generosity of Spinola, who became a friend of Velázquez, and glorifies his name and image. The general died several years before the event was painted, when Breda had already been occupied by the Dutch (Berzal. 2013) for 10 years. The painting also pays homage to King Philip IV, who is portrayed in the painting as a powerful man of might. This is the artist's contribution to Spain's national identity.

"The Surrender of Breda" (Wagner-Pacifici, 2005) is one of a twelvepainting series of the victories of Spanish King Philip IV, and it describes the formal ceremony held on June 8,1625, in which the key to the city was delivered about three days after it surrendered. The artist disregarded the violent aspects of the battle and chose to focus on the outcome - the surrender of the Dutch. "At the center of the painting is the key that the Dutch general is endeavoring to hand over to Ambrogio Spinola, which lost its relevance but was essential from a symbolic point of view. Spinola's receiving of the key is the equivalent of a handshake" (ibid, p. 104).

Some doubt the entire incident, saying that this was a political agreement rather than a surrender in a military battle. That is, Breda did not surrender because it was attacked but rather, to prevent the city's destruction or plunder by the attacking forces, the city gave the forces monetary compensation for the loot that they did not take. Hence, the portrayal of Spanish chivalry is misplaced. The inaccuracy of the painting is evident, for example, in the fact that it depicted the military forces using spears rather than rifles, which were already in use at the time. In addition, Justin of Nassau died in battle and his successor was unable to withstand the siege placed by Spinola. He surrendered in May 1625 and it was he rather than Justin who presented the key to Spinola.

Despite his young age, the artist shows deep sensitivity and a mature psychological understanding in this painting. The surrender is characterized in 
the painting as a civilized act where the Spanish conqueror accepted the Dutch surrender while maintaining the honor of the latter and avoiding revenge. In the painting, Veláazquez illustrates the dramatic event by portraying the two generals, who meet in the center, with humane expressions. In the genre of war paintings, particularly those depicting military victories in the early Modern European period, the victorious conquering commander would appear on horseback while the vanquished would be kneeling submissively, humiliated by the conqueror. This painting radically deviates from this convention, stressing the touching human aspect whereby "an elegant altruistic victory is the true definition of a great leader or commander, and not necessary the cruel ability to defeat a rival on the battlefield" (Berzal, 2013).

The two camps are depicted with many contrasts: On the right - the many Spaniards, victorious and erect, with their direct gaze, organized, strong, and proud, their upright lances against a powerful and protective background. The large, noble horse bursts in and the Spanish flag is proudly hoisted. The spears and lances, drawn tall above the horizon, create the impression that the number of Spanish soldiers was greater than in the painting and that the group is well organized and has considerable military capacity. On the left - the few defeated Dutch with their few short weapons stand as an unorganized rabble, their heads bowed, and the irritable horse as well as the orange flag convey confusion and defeat.

In the painting, the Dutch Justin of Nassau hands over the key to the city gates - both a tangible and symbolic gesture - to his Spanish rival. The surrender is manifested in his body language, expressed by Justin's hand, which conveys failure, concession, and recognition of defeat as it offers the key. This is supplemented by his placement on a lower height than his rival. The painting does not, however, show a victorious commander on a horse and a defeated commander on his knees (Figure 2). The hand of the proud Spanish general, the victorious conqueror who alighted from his horse, is outstretched in an expression of humane compassion and generosity. He gazes at his vanquished rival, and despite his superiority, he places his arm on the other's shoulder in understanding to prevent bowing Justin from kneeling and suffering humiliation. The body language of the Spanish general conveys consideration without patronization. The battle remains in the background as mere clouds of smoke and the focus of the empathic painting is on the compassion towards the surrendering rival rather than on military might and force in battle, defeat and victory trumpets: "Spinola dictated generous surrender conditions to the Dutch, instructing his soldiers to treat them with respect and politeness and to let them leave the place in military parade, unharassed and accompanied by drums" (Bailey, p. 102).

The city was not destroyed. The painting illustrates the fairness of man and of a victorious commander who forbids his subordinates to act in contempt 
towards the defeated and commands them to be considerate. Although only days before they had been killing each other, in the painting the two armies share an atmosphere of reconciliation, peace, and mutual respect.

The third example demonstrates issues of parental authority, parentchild relations, true relations, and parental respect, which are relevant in the postmodern world as well. Universal issues such as these have perturbed humanity from time immemorial, and have found expression in art, narrative fiction, playwriting, and poetry. The renown Dutch artist Rembrandt van Rijn chose to focus on father-son relations and the inter-generational conflict in his painting "The Return of the Prodigal Son" (1661-1669, Figure 3), which demonstrates his deep spiritual and psychological understanding of the human story, through which the observer understands the concepts of love, relationship, guilt, motivation, pride, jealousy, remorse, and forgiveness. The painting focuses on the victory of love, good, and justice. The event is portrayed as an act of human wisdom and spiritual nobility, expressed by the emotional accuracy displayed by Rembrandt and through his chiaroscuro (light and shade), in his portrayal of the reconciliation between the remorseful son and his forgiving father.

This painting originates from a parable in the New Testament - the Gospel of Luke 15: There was a man who had two sons. The older son loyally remained with the father and worked with him in his fields, but the younger son left his father's house with his part of the estate, spent all his money on wild living, lost everything, and was forced to return to his father's house. When his father saw him, he was filled with compassion; he ran to his son, threw his arms around him and kissed him. The father instructed his servants to dress the son in precious clothes and to hold a feast and celebrate. When the older son heard this he complained to his father about the discrimination, as he who had always worked his father's fields loyally had never received any such appreciation as that awarded his brother, who had engaged in a life of sin. The father answered his eldest: For your brother it is right to celebrate and be glad because he had been dead and is alive again; he was lost and is now found.

In the painting the father accepts and embraces his son who repented after a process of self-examination. The conclusion of the story is that one who was exposed to a life of sin but repented is entitled to special treatment and is considered by God to be more worthy than the God-fearing believer who never deviated. In the center of the scene, with its contrasting light and shade, is the figure of the slightly bowed elderly father, his eyes closed, hugging his ragged wandering son who is kneeling before him. The father accepts his son with love and forgiveness, his hands expressing compassion, forgiveness, reconciliation, and healing, while the body language of the son, who rests his head on his father's chest, conveys his honest intentions, although his sheathed 
sword arouses doubts and queries. The son avoids looking into his father's eyes due to his sorrow, discomfort, embarrassment, shame, and remorse. Some contend that he does not wish to look at his father because he is not truly repentant and his return home was only occasioned by his sorry circumstances.

To the father's left stands the elder son, whose red garment resembles that of the father and whose illuminated face attests to his family affiliation, straight backed with folded arms - the rational right covering the emotional left to calm it. He looks on with obvious dissatisfaction and even objection as his father gives in to his brother's ungratefulness. Aside from the father's illuminated face and his acceptance of the son, evident in his body language, the father's illuminated hands have a major role. His two arms embrace the son and defend him, placed as they are on his illuminated back. The hands, which tell the entire story, differ from each other: The left hand is strong and muscular with a masculine, coarse, authoritative expression, and it is the largest and widest of the two. Its fingers are spread and spaced and a certain pressure of the thumb on the son's back is evident despite the gentle contact. This is the hand that reminds the son of his sin as well as of the father's doubts, reservations, and suspicions regarding his son's intentions. The right hand is perceived as feminine; it is smooth, narrower, soft, subtle; its fingers have an elegant nature as they are tight and close to each other. This is the compassionate hand that forgives the son's sins and seeks to stroke, comfort, and pardon. Despite their different texture, the two hands together grant limitless compassion, unconditional love, and eternal forgiveness.

The son's two feet seem to parallel the two hands. The right foot in the rough soled shoe and the bare injured left foot also symbolize the two aspects of the father's attitude to his son's return: The first conveys fatherly toughness, fortifying the strength of the son who is planning his life, while the second conveys maternal softness that defends his vulnerable side (Nouwen, 1994). The dramatic, theatrical, deep, and psychologically charged moment when the father accepts his deviant son was produced by Rembrandt in the last year of his life. His personal experience, life tribulations, and nearing his own end probably played a part in his decision to choose this moving scene of reconciliation (Figure 3).

These three examples are a drop in the sea of knowledge, beauty, academic, and educational treasures contained by the humanities. After all these, is it even possible to imagine a world that is only practical, purposeful, profitable, and cold from a humane and spiritual respect? What about human thought, with its casuistry and subtleties? Are the generations of philosophy destined to be forgotten or erased? If we are dealing with fables, then philosophy has become the "queen" of the non-purposeful, and although several departments of philosophy in various universities have been closed, it appears that it is specifically philosophy that has begun to once again attract 
attention. This is an effect of the development of artificial intelligence, which requires deep and abstract thinking and differs from the needs of the natural sciences. Engaging in the humanities fosters a broad, critical, and creative ability of reasoning.

\section{Conclusion}

In Israel and around the world there is a decline in the status of the humanities, raising questions regarding the significance of their continued existence in a world strongly attracted to values of modernity and technology. In a world of instant responses and immediate gratification, humanist values seem irrelevant. The current study explores the contribution of the humanities in the present world and the need for the academic humanities studies in contemporary Israel.

The examples described above illustrate that the humanities are essential for a critical human society and therefore it is necessary to make sure that these programs continue to exist, but not in their current form. Changes should be made in the study tracks, making them more practical and attractive, such that they speak the "language of the current generation".

In addition, it is necessary to develop study programs that combine disciplines in the humanities with disciplines in the natural sciences, social sciences, and even medical studies. A combination between economics and languages, literature and psychology, art, and education, business management and arts, and more. Constructing interdisciplinary study programs may enhance the status and spare the very existence of these sciences. Developing creativity in teaching the humanities, creative and challenging teaching methods that will differ from monotonous studies that adhere to constant revision, might reinvigorate the humanities and increase the demand for these programs.

It is also important to continue to revitalize the humanities programs raising awareness of decision makers and placing the issue on the public agenda. A previous study ((Davidovitch \& Shiller, 2016), found that the attitude of high school students predicts their future choice of study discipline. Exposing high school students to a humanities-related academic experience may increase motivations to study these disciplines.

This study proposes a shift in orientation from STEM to STEAM, by incorporated humanistic studies into the studies of science-based disciplines (in this acronym, " $\mathrm{A}$ " signifies the arts). This shift originates from a method that sees the disciplines of science, technology, engineering, and mathematics as the disciplines of the future and urges educational systems to embrace 
strategies for promoting these disciplines, yet at the same time, placing humanistic studies as an integral part of academic education. The integration of humanistic studies may have unique value for science-based education, particularly in the era of robotics and technology, and may be an encouraging trend for humanistic studies.). Such a shift may.

The article illustrates the significance of humanistic studies, particularly in an era that challenges the role of the academic campus that offers a variety of means for students' study. The main potential advantage of physical universities and academic institutions, where students and teachers meet, talk, and hold discussions, is in the direct and unmediated relationship that provides a setting for discussions and discourse, which may be sufficient to justify the existence of the universities. This is particularly significant also in light of the concerning data that indicate a significant drop in registration to universities in Israel and around the world, with the current young generation gradually finding less benefits to universities for shaping their personal and professional future.

\section{References:}

1. Assis, E. (2020). Where are the humanities headed? Makor Rishon Supplement (pp. 13-16). March 20.

2. Bailey, A. (2011). Velazquez and the Surrender of Breda, N.Y: Henry Holt and Co. p. 102.

3. Bassnett, S. (2002). Is There Hope for the Humanities in the 21st Century? Arts and Humanities in Higher Education 1(1):101110 - AURO UNIVERSITY.

4. Ben-Ayun, A.n, C. (2011). Attitudes of $4^{\text {th }}-6^{\text {th }}$ grade students in general public schools towards Bible subjects. Journal for Judaism, Zionism, and Eretz Israel, 8, 139-156. [in Hebrew]

5. Berzal,J.(2013)."Velázquez, The Surrender of Breda", https://www.khanacademy.org/humanities/monarchyenlightenment/baroque-art1/spain/a/velzquez-the-surrender-ofbreda. Council for Higher Education, Document from August 7, 2013. [in Hebrew]

6. Dancy, R.M. (2004). Plato's Introduction of Forms, Cambridge: Cambridge University Press, p. 18

7. Davidovitch, N., \& Shiller, Z. (2016). Skill-based teaching: Teaching robotics and mechatronics to mechanical engineers. American Journal of Engineering Education. 7(1), 29-36.

8. Dorot, R. (2013). Symbolic Allusion Temporal Illusion, Sussex Academic Press. 
9. Davidovitch, N. (2004) Students knowledge in Jewish heritage and culture. Moreshset Yisrael - A Journal of Judaism and Zionism, Nov, 100-122.

10. Elior, R. (2011). The struggle over the humanities. Kivunim Hadashim, 25, 73-103. [in Hebrew]

11. Frank, J.D. \& Gabler, J. (2006). Reconstructing the University. Worldwide Shifts in Academia in the 20th Century. Stanford, CA: Stanford Univ. Press.

12. Furstenberg, Y. (2020). Where are the humanities headed? Makor Rishon Supplement (pp. 13-16). March 20.

13. Goldman, S. (2014) Harvard and the humanities. First Things, 239, 2021.

14. Lamm, Z. (1993). The Pedagogical Meaning of the Problem of the Religious Structure. Position paper submitted to the Pedagogical Secretariat of the Ministfy of Education and Culture. [in Hebrew]

15. Lamm, Z. (1999). Between the educational ideologies and the teaching methods in Israeli schools from their beginning until establishment of the state. In R. Globman \& Y. Iram (Eds.), Development in Teaching: The Israeli Case (pp. 29-31). Tel Aviv: Ramot, Tel Aviv University. [in Hebrew]

16. Noam, V. (2020). Where are the humanities headed? Makor Rishon Supplement (pp. 13-16). March 20.

17. Nouwen, H.J.M. (1994). The Return of the Prodigal Son. New York: Doubleday Publishing Group.

18. Pepper, S. (2011). Battle pictures and military scenes. Grove Art, online, March 22.

19. Richards, G. (2016). “Oh, The Humanities! Why STEM Shouldn't Take Precedence over the Arts." Arizona State University - Project Humanities. Arizona State University. Web. 05 Mar. 2017. http://www.visual-arts-cork.com/famous-paintings/school-ofathens.htm

20. Rinon, Y. (2014). The Crisis in the Humanities. Tel Aviv: Hakibbutz Hameuchad. [in Hebrew]

21. Shamir, E. (2012). Collapsing values in a disappearing world Educating for values in a "changing society". Kivunim Hadashim, 26, 161-171. [in Hebrew]

22. Shamir, Z. (2009). The study of Hebrew Literature is dying out. Kivunim Hadashim, 19, 73-80. [in Hebrew]

23. Shamir, Z. (2012). University politicization is deepening under the patronage "academic freedom"/ Kivunim Hadashim, 26, 91-106. [in Hebrew] 
24. Shenhar, A. (2007). Crisis in Jewish studies - and the academic world is silent. Kivunim Hadashim, 16, 77-82. [in Hebrew]

25. Triger, Z. (2007). Law and theatre as bridges between the humanities and the social sciences - an article in three scenes. Din Udvarim, 3(1), 63-105. [in Hebrew]

26. Wagner-Pacifici, R. (2005). The Art of Surrender: Decomposing Sovereignty at Conflict's End. Chicago: University of Chicago Press.

27. Yisraeli, O. (2020). Where are the humanities headed? Makor Rishon Supplement (pp. 13-16). March 20.

28. Zakovitch, Y. (2005). Distancing requires proximity. Nos'im Behinuch, 4, 7-17. [in Hebrew]

\section{Paintings}

Figure 1

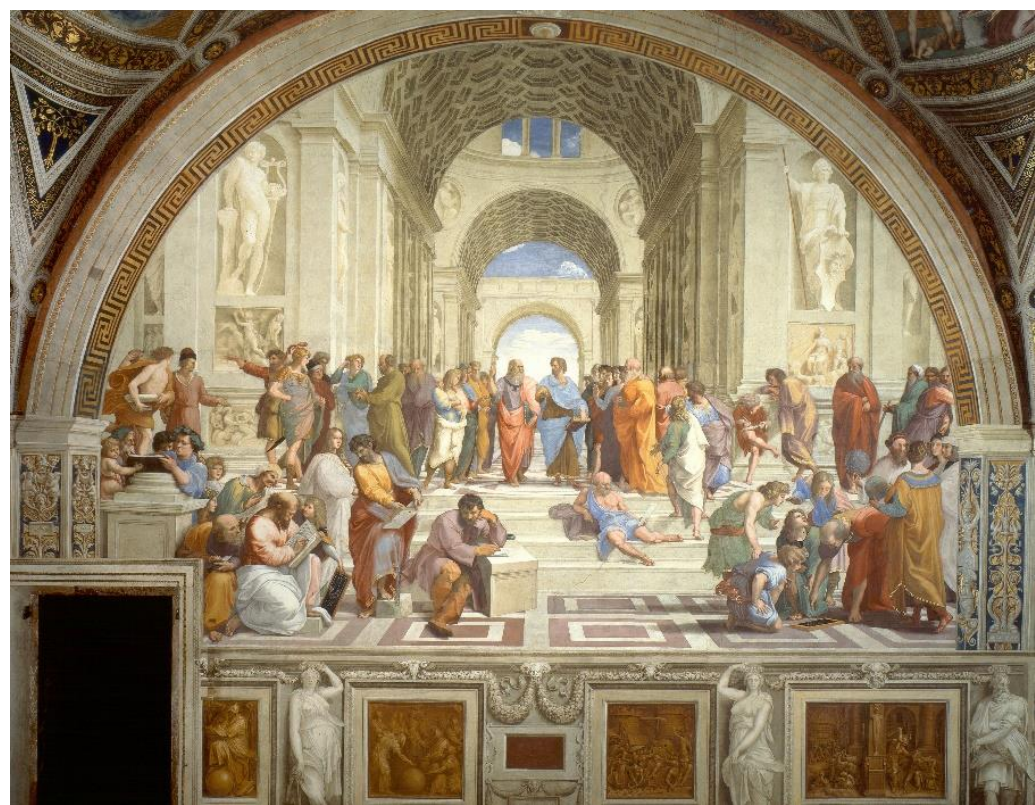

Raphael Sanzio, “The School of Athens”, 1509-1511

Musei Vaticani, Stanze di Raffello 
Figure 2

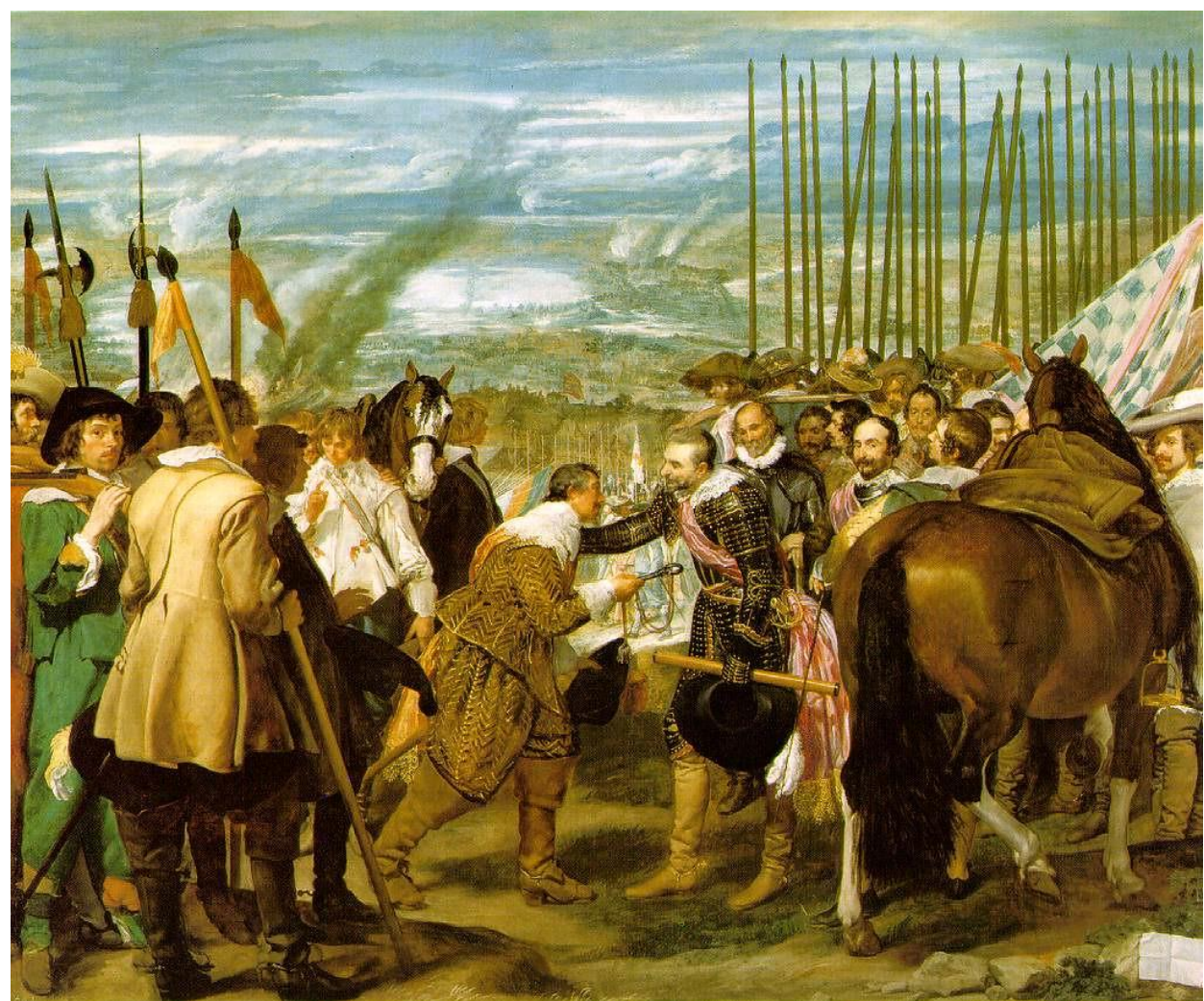

Diego Velazquez, "The Surrender of Breda" / "The Lances", 1634-1635 Museo del Prado, Madrid, Spain 
Figure 3

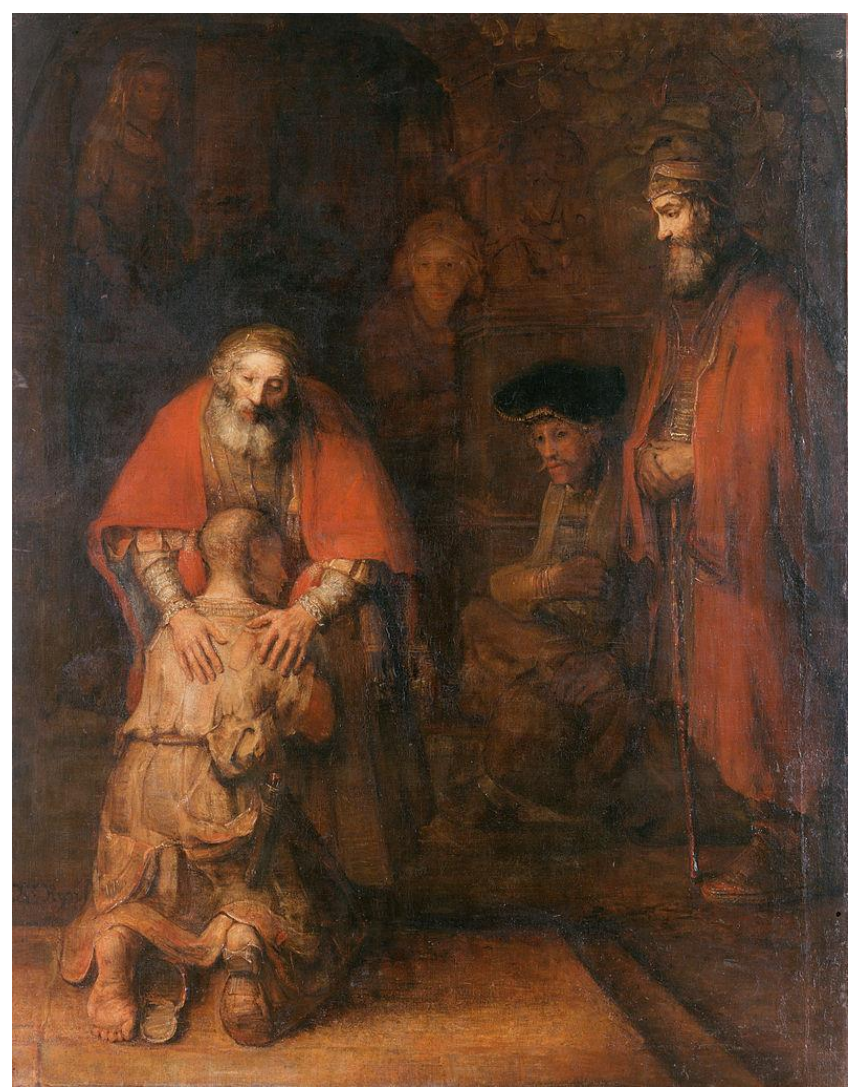

Rembrandt van Rijn, “The Return of the Prodigal Son”, 1661-1669 Hermitage Museum, Saint Petersburg, Russia 